\section{Pasquale Montagna}

\section{P. Montagna ( $\square)$}

Institute of Clinical Neurology,

University of Bologna Medical School,

Via Ugo Foscolo 7, I-40123 Bologna, Italy

e-mail: pmontagn@ neuro.unibo.it

Tel.: +39-051-6442179

Fax: +39-051-6442165

\section{The genetics of migraine}

linkage studies have also been performed in migraine with and without aura, the so-called typical migraines, without however definite results up to now.

Key words Migraine $\cdot$ Genetics $•$ Familial hemiplegic migraine $•$ Linkage $\cdot$ Association

\section{Introduction}

Migraine is a disease with a rather high prevalence among the general population, with lifetime rates ranging from $18 \%$ to $25 \%$ in certain age ranges and among women. Migraine can be diagnosed only by means of clinical criteria, and has no recognized laboratory markers. Moreover, there is no general agreement among researchers that migraine forms a unique nosological category, and it is rather probable that different, independent types of migraine exist as a result of diverse pathophysiological mechanisms. It is therefore difficult to draw definite conclusions about the genetic mechanisms underlying the pathophysiology of migraine. Several studies have examined the genetic transmission of migraine, and others have been devoted to linkage and association. These efforts have resulted in the discovery of the first gene clearly implicated in migraine etiology and of another locus of linkage, both for familial hemiplegic migraine (FHM). The genetic patterns of migraine and FHM are briefly reviewed here, but for more details of the association studies the reader is referred to a previous review [1].

\section{Migraine with and without aura: genetic patterns}

Migraine is significantly more frequent in families along the maternal line as compared to the paternal line. The onset of the disease is clearly related to the genetic "load" of the proband, and occurs earlier among probands with a higher number of affected relatives, especially parents. A family history of migraine is particularly likely when age at onset in the proband is below 20 years [2].

A segregation study of 128 Italian families observed at the Headache Center in Bologna found that 56\% of 
probands with migraine had at least one affected parent, confirming the relationship between family prevalence and age at onset [3]. All subsequent studies concurred that relatives of probands with migraine have a higher disease risk. A very high percentage, $85 \%$, of first-degree relatives affected with migraine was found by D'Amico et al. [4]. In two studies of the disease risk in relatives of migraine probands, Russell et al. [5, 6] calculated that the risk for first-degree relatives was 3-fold greater in probands with migraine without aura, and 2-fold greater for probands with migraine with aura. These authors went on to study the comparative risk of migraine in spouses versus relatives of migraine sufferers, who share a similar environment but have presumably distinct genotypic backgrounds. The risk for spouses of migraine sufferers was not significantly different from that of the general population, a solid indication that the increased disease risk among relatives was indeed related to genetic factors. Later studies by the same group in Copenhagen showed this genetic determination to be stronger in the case of migraine with aura, with a disease risk for first-degree relatives ranging from 2 to 6 times that found in the control population.

A different type of study of 90 Italian patients with migraine headaches led us to calculate the so-called heritability index of Falconer [7]. This measure of the relative genetic versus environmental determination of a disease varies between 1 (complete) and 0 (absent). Migraine with aura had a heritability index of 0.72 and migraine without aura of 0.96 , values in both cases highly indicative of a strong genetic determination [8].

Studies of the disease risk in relatives leave small doubts that there is indeed a major genetic causation in migraine. Detailed studies of migraine pedigrees, however, all failed to indicate a clear transmission modality of the disease, at least according to the rules of simple mendelian transmission valid for monogenetic traits. Indeed, neither a dominant nor recessive autosomal modality can be unequivocally substantiated, and mitochondrial and $\mathrm{X}$ linked transmissions have been excluded since there is ample evidence for male-to-male transmission. Most authors have concluded in favor of a polygenetic determination, i.e. they considered migraine to be a multifactorial disease. D' Amico et al. [4] considered migraine to be a disease with "sex-limited" transmission, meaning that environmental or genetic factors related to the sex of the proband modify the expression of the disease, which however is autosomal and otherwise conforms to regular mendelian rules. This is a rather useful concept, which explains the overall higher prevalence of migraine among women in all age groups except pre-pubertal children. The concept of sex-limited transmission may also be applied to the genetics of cluster headache, another primary headache in which the sex pattern is reversed.
Another traditional genetic approach is represented by the study of twins: disease prevalence can be compared among pairs of mono- and dizygotic twins and, more appropriately, among monozygotic twins raised together or apart. All twin studies have documented a higher prevalence of migraine among monozygotic than dizygotic twins, in the range of $22 \%-60 \%$ versus $5 \%-20 \%$. By averaging all of the relevant studies, Merikangas [9] came up with a heritability of about 0.38 (in a range from 0 to 1 ), which again confirms that migraine has a genetic determination, but nonetheless leaves a great part of causation to environmental factors. Higher rates of heritability, 0.5 and 0.7 , have been more recently found $[10,11]$.

\section{Familial hemiplegic migraine}

FHM is considered to represent a subtype of migraine with aura, and its autosomal dominant genetic transmission has been recognized very early. FHM is the only subtype of migraine which conforms to simple mendelian transmission and indeed the phenotype and sex ratio in FHM are quite distinct. This has much helped genetic analysis.

In 1993 Joutel et al. [12] mapped FHM to a locus on chromosome 19, while performing genetic studies on CADASIL, an unrelated condition with syndromic migraine with aura among the clinical features. Later Ophoff et al. [13] found that the gene involved in FHM pathogenesis was the CACNA1A gene encoding a P/Q type calcium channel widely expressed in presynaptic terminals of neurons, especially the Purkinje cells of the cerebellum.

Four missense mutations have been found in the CACNA1A gene in families with FHM. Interestingly, frameshift mutations in the same gene have been found in pedigrees affected with episodic ataxia type 2 (EA-2). Later, Zhuschenko et al. [14] found that spinocerebellar ataxia type 6 (EA-6), a progressive type of ataxia with cerebellar atrophy, was due to intragenic CACNA1A CAG repeats, thus establishing that FHM is a disease allelic not only with EA2 but also with SCA-6. Several mutations in CACNA1A have been reported in FHM pedigrees, some but not all of them are associated with progressive cerebellar ataxia [1]. Why some CACNA1A mutations lead to cerebellar atrophy while others do not remains unclear. This difference seems unrelated to the characteristics of the mutated channel, since experimental studies in animals have shown that mutations responsible for cerebellar atrophy may cause either gain or loss of function.

Knock-out mice lacking the murine equivalent of human CACNA1A developed cerebellar ataxia, but the pathogenesis remains elusive. Epileptic seizures occur in these mice, and the intriguing possibility that migraine and epilepsy, 
both paroxysmal disorders, represent parts of a spectrum of calcium channelopathies has been raised by the Leiden school $[14,15]$. In light of established pathogenic theories, it is difficult to envisage why the cerebellum would be involved in a migraine disorder, and how reversible paralysis could occur, unless we postulate some disorder of neural excitability linked to calcium channel malfunctioning and possibly leading to a persistent and travelling neuronal depolarization, e.g. spreading depression. Spreading depression is not, however, a necessarily good pathogenic model for migraine aura. Even though a rare disease, FHM has been shown to be genetically heterogeneous; linkage has been established on chromosome 1 to two different loci, 1q21-23 [16] and 1q31 [17], and other FHM families are unlinked to both CACNA1A and chromosome 1. Therefore, there are at least 4 and probably more loci responsible for FHM.

\section{The "typical" migraines: association and linkage studies}

At first, the discovery of the CACNA1A gene responsible for FHM led to the proposition that this gene was implicat- ed in the pathogenesis of the more common types of migraine, e.g. those with and without aura, henceforth called "typical" migraines. Some evidence in favor of this idea was found by May et al. [18] and Nyholt et al. [19], but several other studies have instead given negative results. Sequencing of the CACNA1A gene in selected families has proven negative, and as yet no family has been reported with non-hemiplegic migraine and a mutation of CACNA1A. This makes CACNA1A a poor candidate gene for the typical migraines.

Finally, several association studies performed in migraine have led to positive findings which were later disputed [1]. Linkage studies have predictably proved negative [20]. Surprisingly, in view of the female preponderance of migraine, Nyholt et al. [19] identified a linkage with the X chromosome (Xq24-28) in 2 families. The typical migraines continue, however, to represent a genetic challenge, and sure proof of the involvement of definite genes is still lacking. It is hoped that this scenario will change in the near future.

Acknowledgements Supported by Murst ex-60\% 1999-2000 and CNR no. 99.02536.CT04 grants. I thank Ms. A. Laffi who helped with the manuscript, and Ms. A. Collins who revised the English.

\section{References}

1. Montagna P (2000) Molecular genetics of migraine headaches: a review. Cephalalgia 20:3-14

2. Baier WK (1985) Genetics of migraine and migraine accompagnèe: a study of eighty-one children and their families. Neuropediatrics 16:84-91

3. Devoto M, Lozito A, Staffa G, D’Alessandro R, Sacquegna T, Romeo G (1986) Segregation analysis of migraine in 128 families. Cephalalgia 6:101-105

4. D'Amico D, Leone M, Macciardi F, Valentini S, Bussone G (1991) Genetic transmission of migraine without aura: a study of 68 families. Ital J Neurol Sci 12:581-584

5. Russell MB, Hilden J, Sorensen SA, Olesen J (1993) Familial occurrence of migraine without aura and migraine with aura. Neurology 43:1369-1373

6. Russell MB, Iselius L, Olesen J (1996) Migraine without aura and migraine with aura are inherited disorders. Cephalalgia 16:305-309

7. Falconer DS (1965) The inheritance of liability to certain diseases, estimated from the incidence among relatives. Ann Hum Genet 29:51-76
8. Mochi M, Sangiorgi S, Cortelli P, Carelli V, Scapoli C, Crisci M, Monari L, Pierangeli G, Montagna P (1993) Testing models for genetic determination in migraine. Cephalalgia 13:389-394

9. Merikangas KR (1996) Genetics of migraine and other headache. Curr Opin Neurol 9:202-205

10. Kallela M, Wessman M, Farkkila M, Palotie A, Koskenvuo M, Honkasalo ML, Kaprio J (1999) Clinical characteristics of migraine concordant monozygotic twin pairs. Acta Neurol Scand 100:254-259

11. Gervil M, Vlrich V, Kyvik KO, Olesen J, Russel MB (1999) Migraine without aura: a population-based twin study. Ann Neurol 46:606-611

12. Joutel A, Bousser MG, Biousse V, Labauge $\mathrm{P}$, Chabriat $\mathrm{H}$, Nibbio A, Maciazek J, Meyer B, Bach MA, Weissenbach J (1993) A gene for familial hemiplegic migraine maps to chromosome 19. Nat Genet 5:40-45
13. Ophoff RA, Terwindt GM, Vergouwe MN, van Eijk R, Oefner PJ, Hoffman SM, Lamerdin JE, Mohrenweiser HW, Bulman DE, Ferrari M, Haan J, Lindhout D, van Ommen GJ, Hofker MH, Ferrari MD, Frants RR (1996) Familial hemiplegic migraine and episodic ataxia type- 2 are caused by mutations in the $\mathrm{Ca} 2+$ channel gene CACNL1A4. Cell 87:543-552

14. Zhuchenko O, Bailey J, Bonnen P, Ashizawa T et al (1997) Autosomal dominant cerebellar ataxia (SCA6) associated with small polyglutamine expansions in the alpha IA-voltagedependent calcium channel. Nat Genet 15:62-69

15. Terwindt GM, Ophoff RA, Haan J et al (1998) Migraine, ataxia and epilepsy: a challenging spectrum of genetically determined calcium channelopathies. Dutch Migraine Genetics Research Group. Eur J Hum Genet 6:297-307 
16. Ducros A, Joutel A, Vahedi K, Cecillon M, Ferreira A, Bernard E, Verier A, Echenne B, Lopez de Munain A, Bousser MG, Tournier-Lasserve E (1997) Mapping of a second locus for familial hemiplegic migraine to 1q21q23 and evidence of further heterogeneity. Ann Neurol 42:885-890

17. Gardner K, Barmada MM, Ptacek LJ, Hoffman EP (1997) A new locus for hemiplegic migraine maps to chromosome 1q31. Neurology 49:1231-1238
18. May A, Ophoff RA, Terwindt GM et al (1995) Familial hemiplegic migraine locus on 19p13 is involved in the common forms of migraine with and without aura. Hum Genet 96:604-608

19. Nyholt DR, Curtain RP, Griffiths LR (2000) Familial typical migraine: significant linkage and localization of a gene to Xq24-28. Hum Genet 107:18-23
20. Monari L, Mochi M, Valentino ML, Arnaldi C, Cortelli P, De Monte A, Pierangeli G, Prologo G, Scapoli C, Soriani S, Montagna P (1997) Searching for migraine genes: exclusion of $290 \mathrm{cM}$ out of the whole human genome. Ital J Neurol Sci 18:277-282 